\title{
PLASMA TREATMENT FOR SILICONE RUBBER CONTACT LENS SURFACE
}

\author{
MASAMITSU KURIAKI \\ Department of Research and Development, Nippon Contact Lens Inc., \\ 3-10 Yoshimoto-cho, Nakagawa-ku, Nagoya, 454 Japan.
}

Plasma treatment was applied as the technique of wettable treatment on silicone rubber (SR) contact lenses (CL) surface. A homemade apparatus was equipped with electric source of $13.56 \mathrm{MHz}$ and outer electrode of capacity load (Fig. 1). N-vinylpyrrolidone (NVP) was selected as monomer of plasma treatment in consequence of some experiments related with the wettability (Tab. 1) and the durability of plasma treatment surface (Fig. 2 and Fig. 3)

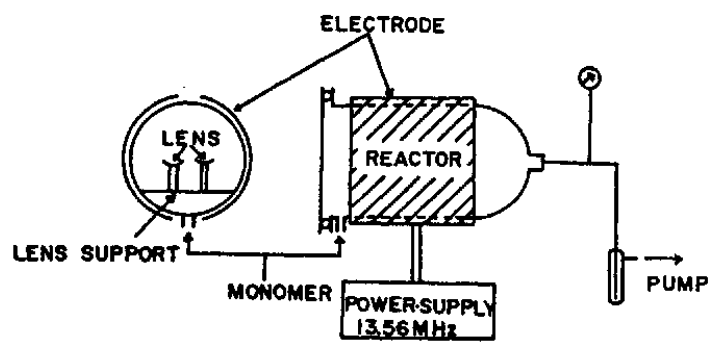

Fig. 1. The sketch of apparatus for plasma polymerization.

Tab. 1 The critical surface tension on plasma polymerized layer. Samples are treated two cycles with autclave into water (one cycle: 121 ${ }^{\circ} \mathrm{C}-20 \mathrm{~min}$ ).

\begin{tabular}{lcc}
\hline \multirow{2}{*}{ Monomer } & \multicolumn{2}{c}{ Critical surface tension } \\
& \multicolumn{2}{c}{ (dyn/cm) } \\
\cline { 2 - 3 } & Rablel's method & Zisman plot \\
\hline NVP & 70 & 22.8 \\
HEMA & 69.5 & 29.3 \\
EG & 65.5 & 25.2 \\
Nontreated & 24 & 15.6 \\
\hline
\end{tabular}

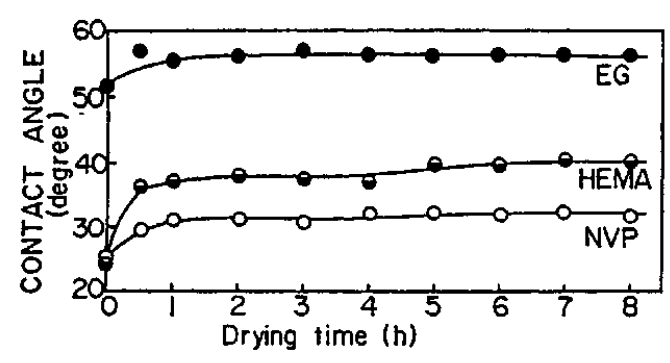

Fig. 2 Change in surface wettability of SRCL after drying at room temperature, monomer: NVP, HEMA, and EG.

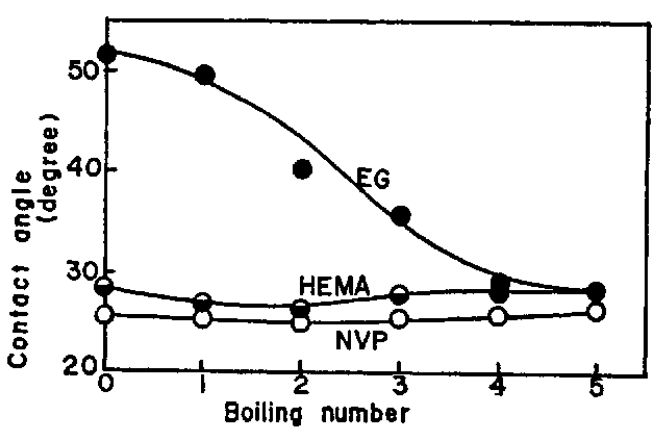

Fig. 3 Change in surface wettability of SRCL after boiling into water, monomer: NVP, HEMA, and EG. 
The best suitable condition of plasma treatment were 40 watt, 0.1 to 0.2 torr and 60 seconds (Tab. 2).

The plasma treatment surface was able to tolerate for drying at room temperature, boiling in water and rubbing at CL cleaning (Fig. 4, Fig. 5, and Fig. 6).

Tab.2 The relation of hydrophilic contact angle and electric power

\begin{tabular}{llllll}
\hline $\begin{array}{l}\text { Power (watt) } \\
\begin{array}{l}\text { Contact angle } \\
\text { (degree) }\end{array}\end{array}$ & 20 & 30 & 40 & 50 & 60 \\
& & 27.8 & 24.2 & 26.7 & 27.8 \\
\hline measured method: air bubble method. &
\end{tabular}

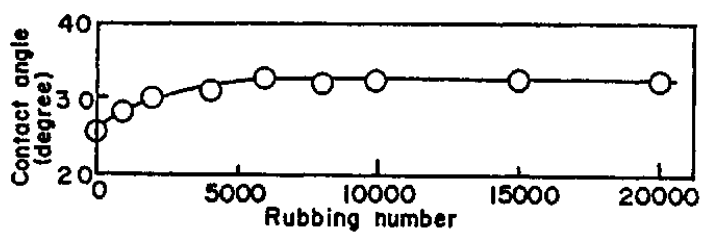

Fig.4 Change in surface wettability of plasma polymerized SRCL. Samples are treated by repeated rubbing.

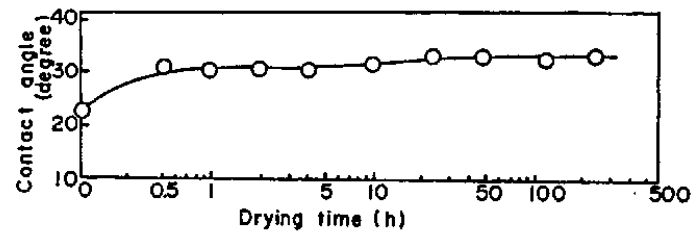

Fig. 5 Change in surface wettability of plasma polymerized SRCL. Samples are left standing in dry condition at room temperature.

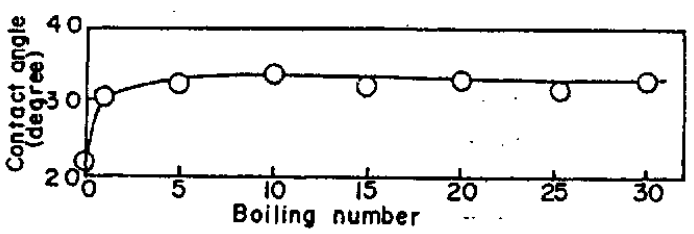

Fig.6 Change in surface wettability of plasma polymerized SRCL. Samples were left standing in boiling water (one cycle: about $15 \mathrm{~min}$. at $\left.100^{\circ} \mathrm{C}\right)$.

As conclusion, it was considered that the plasma treatment surface with NVP was superior to the surface treatment on SRCL.

\section{References}

1. Y. Mizutani, Y. Miwa, M. Kuriaki, S. Nozaki and Y. Mizutani, J.Japan Contact Lens Soc., $22(1980) 1$.

2. M. Kuriaki, S. Nozaki, T. Sato, and Y. Mizutani, J.Japan Contact Lens Soc., 24(1982)189.

3. M. Kuriaki, M. Hasebe, Y. Miwa and Y. Mizutani, Kobunshi Ronbunshu, 42(1985)841. 